\title{
Effect of Packaging Methods on Colour, Lipid Quality and Microbial Growth of Beef Patties Enhanced with Flaxseed Flour
}

\author{
Irem Altuntas and Sadettin Turhan* \\ Department of Food Engineering, Ondokuz Mayis University, 55139 Samsun, Turkey
}

\begin{abstract}
In this study, the effect of packaging methods [aerobic packaging (AP), vacuum packaging (VP) and modified atmosphere packaging (MAP: $75 \% \mathrm{~N}_{2}, 25 \% \mathrm{CO}_{2}$ )] on colour, lipid quality and microbial growth of beef patties enhanced with flaxseed flour was investigated during storage at $2 \pm 1^{\circ} \mathrm{C}$ for $10 \mathrm{~d} . L$ and $a$ values of beef patties packaged in MAP and VP were higher $(p<0.05)$ than that of the samples packaged in AP. Packaging in MAP and VP retarded the lipid oxidation (TBA value) and inhibited the bacterial growth of beef patties enhanced with flaxseed flour. Furthermore, TBA values in beef patties were correlated with $a$ values $(\mathrm{r}=-0.340 ; p<0.05)$. Packaging in MAP was more effective than packaging in VP for inhibiting microbial growth. The samples packaged in VP lost their shape due to the compression by external atmosphere. Packaging treatment had no significant effect on saturated fatty acid (SFA), monounsaturated fatty acid (MUFA) and polyunsaturated fatty acid (PUFA) levels in beef patties. The $a$ and $b$, TBA and MUFA values changed during storage time. TBA values for beef patties increased during storage time, but did not reach to the limit value $(1 \mathrm{mg} / \mathrm{kg})$ until the end of the storage time. The results suggest that the shelf life of beef patties enhanced with flaxseed flour can be extended by packaging in MAP.
\end{abstract}

Key words: beef patties, packaging methods, colour, lipid quality, microbial growth

\section{Introduction}

Beef is considered to be a highly nutritious and valued food. The importance of meat as a source of high biological value protein and micronutrients (including for example vitamins A, B6, B12, D, E, iron, zinc, selenium) is well recognised. However, over the last 10-15 years, these positive attributes have often been overshadowed due to the prominence given to several negative attributes. The latter include the perception that beef contains high amounts of fat which is rich in saturated fat, associations between red meat and cancer, and non-nutritional issues such as BSE (Scollan et al., 2006). Nowadays, the meat industry tries to offer the consumer healthy products obtained by different strategies, improving the nutritional quality of food by the modification of the lipid fraction: increasing monounsaturated fatty acids (MUFA) and polyunsaturated fatty acids (PUFA) fractions (Rubio et al., 2008). Modification of the lipid fractions of meat and meat products may be achieved by addition of vegetable

\footnotetext{
*Corresponding author: Sadettin Turhan, Department of Food Engineering, Ondokuz Mayis University, 55139 Samsun, Turkey. Tel: 90-362-312-1919; Fax: 90-362-457-6034; E-mail: sturhan@ omu.edu.tr
}

oils, fish oils (Arihara, 2006; Fernandez-Gines et al., 2005; Jimenez-Colmenero et al., 2001; Valencia et al., 2008) and flaxseed flour (Bilek and Turhan, 2009). Flaxseed has recently gained attention as a "functional food" because of its unique nutrient profile and potential to affect the risk and course of cardiovascular disease and some cancers, particularly hormone-dependent cancers such as prostate and breast. Flaxseed has a unique fatty acid profile. It is high in PUFA (73\% of total fatty acids) and moderate in MUFA (18\%). Linoleic acid, an omega6 fatty acid, constitutes about $16 \%$ of total fatty acids, whereas $\alpha$-linolenic acid constitutes about $57 \%$, the highest of any seed oil (Bilek and Turhan, 2009).

Microbial growth, discolouration and lipid oxidation are important factors determining shelf life and consumer acceptance of patties. The patties can easily be contaminated by microorganisms from raw materials (ground beef and spices), equipment and employees (Ozturk et al., 2010). Addition of flaxseed flour has been shown to increase PUFA content, mainly C18:2n-6 and C18:3n-3, in beef patties (Bilek and Turhan, 2009). High percentage of PUFA makes these products highly sensitive to oxidation. The oxidation process greatly reduces the nutritional value of lipids and leads to the development of undesirable rancidity and potentially toxic reaction products (Tang 
et al., 2001), whereas microbial growth may cause both spoilage and foodborne diseases (Fernandez-Lopez et al., 2005). Therefore, preventing or retardation of the oxidation process and bacterial growth in beef patties are factors that can have a significant contribution towards the extension of shelf life.

Vacuum (VP) and modified atmosphere packaging (MAP) techniques are used in the food industry to extend the shelf life of foods by controlling microbial growth and chemical degradations (Ozturk et al., 2010; Seydim et al., 2006). Various authors (Gok et al., 2008; Ozturk et al., 2010; Parra et al., 2010; Rubio et al., 2008) have studied the effect of vacuum and MAP packaging on microbiological and physicochemical properties of meat and meat products. In a previous study, Bilek and Turhan (2009) investigated the enhancement of the nutritional status of beef patties by adding flaxseed flour and indicated that flaxseed flour can be used up to $6.0 \%$ for enhance the nutritional value and health benefits of beef patties with minimal changes in composition and/or sensory properties.

Therefore, our objective was to evaluate the effect of three packaging methods (aerobic packaging, vacuum packaging and MAP: $75 \% \mathrm{~N}_{2}, 25 \% \mathrm{CO}_{2}$ ) and the storage time $(1,4,7$ and $10 \mathrm{~d})$ on colour, lipid quality and microbial growth of beef patties enhanced with flaxseed flour.

\section{Material and Methods}

\section{Preparation of beef patties}

Ground beef (moisture 63.04\%, fat 16.66\%) and beef fat (moisture $11.28 \%$, fat $86.76 \%$ ) were purchased from a butchers shop. Flaxseed (moisture 6.57\%, fat 37.65\%), salt and garlic powder were purchased from a local market and flaxseed are used in the form of flour after being ground with a mill (IKA A 11, Germany). Beef patties were prepared by mixing of $82.5 \%$ ground beef, $10 \%$ beef fat, $5.0 \%$ flaxseed flour, $1.5 \%$ salt and $1.0 \%$ garlic powder for $20 \mathrm{~min}$ by hand with gloves. Then, patties (40 g) were formed from the mix. The formed patties were divided into three equal parts and were packaged with three methods including aerobic packaging (AP), vacuum packaging (VP) and MAP $\left(75 \% \mathrm{~N}_{2}, 25 \% \mathrm{CO}_{2}\right)$.

\section{Packaging of beef patties and storage}

For AP, seven beef patties were packaged in polyamide bags (Aksedef Plastic, Turkey). The polyamide bags had an oxygen permeability of $52.4 \mathrm{~cm}^{3} / \mathrm{m}^{2} / 24 \mathrm{~h}$ at $1 \mathrm{~atm}$ and $23^{\circ} \mathrm{C}$. For VP, seven beef patties were placed in polya- mide bags (Aksedef Plastic, Turkey) containing an oxygen permeability of $52.4 \mathrm{~cm}^{3} / \mathrm{m}^{2} / 24 \mathrm{~h}$ at $1 \mathrm{~atm}$ and $23^{\circ} \mathrm{C}$, and vacuum sealed using vacuum packager (model PM 650, Unal Machine, Turkey) for $8 \mathrm{~s}$. For MAP, seven beef patties were put into $\mathrm{PVC} / \mathrm{PE} / \mathrm{EVOH} / \mathrm{PE}$ gas impermeable trays (Cokay Plastic, Turkey). Packages were evacuated, filled with a modified atmosphere containing 75\% nitrogen and $25 \%$ carbon dioxide and automatically heat sealed by a packaging unit (model KVG-010, Unal Machine, Turkey) with $89.4 \mu \mathrm{m}$ thick PA/PE film (Elite Representative Import Export and Trade. Co. Ltd., Istanbul, Turkey). The PA/PE film had an oxygen permeability of $6.04 \mathrm{~cm}^{3} / \mathrm{m}^{2} / 24 \mathrm{~h}$ at $1 \mathrm{~atm}$ and $23^{\circ} \mathrm{C}$, and nitrogen permeability of $1.64 \mathrm{~cm}^{3} / \mathrm{m}^{2} / 24 \mathrm{~h}$ at $1 \mathrm{~atm}$ and $23^{\circ} \mathrm{C}$, and carbon dioxide permeability of $16.42 \mathrm{~cm}^{3} / \mathrm{m}^{2} / 24 \mathrm{~h}$ at $1 \mathrm{~atm}$ and $23^{\circ} \mathrm{C}$.

The preparation and packaging of beef patties was performed at about $7^{\circ} \mathrm{C}$. The packaged patty samples were stored at $2 \pm 1^{\circ} \mathrm{C}$ a home-type refrigerator for $10 \mathrm{~d}$. Samples were randomly drawn for analysis at the evaluation periods. The colour, TBA value and microbial growth were analysed on 1, 4, 7 and $10 \mathrm{~d}$ of storage. Fatty acid composition of samples was evaluated on 1 and $10 \mathrm{~d}$ of storage. All analyses were performed in triplicate.

\section{Colour and TBA value}

The colour of beef patties was measured using the Hunter Lab system with a colorimeter (Minolta CR 300), calibrated with a white tile (Minolta calibration plate, No. 21733001, $\mathrm{Y}=92.6, \mathrm{x}=0.3136, \mathrm{y}=0.3196)$ at $2^{\circ}$ observation angle with a $\mathrm{C}$ illuminant. Three beef patties per batch were randomly selected and three readings were taken from each beef patty. Hunter $L^{*}$ (lightness; 100=white, 0 =black), $a^{*}$ (redness; +, red; -, green), $b^{*}$ (yellowness; +, yellow; -, blue) values were recorded.

TBA value was determined according to the water vapour distillation method of Tarladgis et al. (1960). The rose-pink colour produced by reaction between malondialdehyde (MDA) and 2-thiobarbutiric acid $\left(\mathrm{C}_{4} \mathrm{H}_{4} \mathrm{~N}_{2} \mathrm{O}_{2} \mathrm{~S}\right)$ was measured at $538 \mathrm{~nm}$. The TBA value was expressed as milligram of malondialdehyde per kilogram of sample.

\section{Fatty acid composition}

Total lipids were extracted by the method of Bligh and Dyer (1959). Fatty acid composition was determined after methylation (ISO, 1978) by GC-MS (Shimadzu model of QP2010 Plus, Japan) using a Teknokroma TR-CN 100 column (60 m ×0.25 mm I.D., $0.20 \mu \mathrm{m})$ (Teknokroma, Spain). The temperature of the injector port and detector 
was held at $250^{\circ} \mathrm{C}$. The injected volume was $1.0 \mu \mathrm{L}$. The carrier gas was helium at a pressure of $200 \mathrm{kPa}$. The split ratio was 1:100. The temperature of the column was held at $90^{\circ} \mathrm{C}$ for $7 \mathrm{~min}$, raised to $240^{\circ} \mathrm{C}$ at $5{ }^{\circ} \mathrm{C} / \mathrm{min}$ and finally held at $240^{\circ} \mathrm{C}$ for $10 \mathrm{~min}$. Fatty acids were identified by comparison of their retention times with those of authentic standards (Supelco 37 Components FAME Mixture, USA) and reported as the percentage of total fatty acids determined.

\section{Microbiological analysis}

For microbiological analysis, patty samples $(10 \mathrm{~g})$ were transferred aseptically into individual stomacher bags, containing $90 \mathrm{~mL}$ of sterile saline solution $(0.85 \% \mathrm{NaCl})$ and homogenized in a stomacher for $1 \mathrm{~min}$. For each sample, appropriate serial decimal dilutions were prepared in saline solution $(0.85 \% \mathrm{NaCl})$ and the surface plate method was used for enumeration.

The microbiological analyses made on the samples were: total aerobic mesophilic bacteria (TAMB) determined on Plate Count Agar (PCA, Merck) incubated at $25^{\circ} \mathrm{C}$ for 5 $\mathrm{d}$, psychrotrophic bacteria on PCA incubated at $7^{\circ} \mathrm{C}$ for $10 \mathrm{~d}$, coliform bacteria on $3 \mathrm{M}$ Petrifilm Coliform Count Plate (Bioser, Spain) incubated at $36^{\circ} \mathrm{C}$ for $24 \mathrm{~h}$ and $S$. aureus on 3M Petrifilm S. aureus Count Plate (Scharlau, Spain) incubated at $36^{\circ} \mathrm{C}$ for $24 \mathrm{~h}$. Results were expressed as Log CFU/g.

\section{Statistical analysis}

The data obtained from three replications were analyzed as a completely randomized design procedure using the general linear model procedure of the SPSS statistical package program (SPSS Inc., USA). The model included packaging method (AP, VP and MAP) and storage time $(1,4,7$ and $10 \mathrm{~d})$ as main effects, and all their interactions. The differences among means were tested for significance $(p<0.05)$ by Duncan's multiple range test. Furthermore, a correlation procedure (Pearson's correlation coefficient) was performed to evaluate any relationship between $a$ and TBA values. The results of the statistical analyses were shown as mean values \pm standard deviation in the tables for four storage times and three packaging methods.

\section{Results and Discussion}

\section{Colour and TBA value}

The effect of packaging methods and storage time on the Hunter Lab attributes and TBA value of beef patties enhanced with flaxseed flour are shown in Table 1. As can be seen, packaging treatment had a significant ( $p<$ 0.01 ) effect on lightness ( $L$ value) and beef patties packaged in MAP and VP were lighter $(p<0.05)$ than the samples packaged in AP. An interaction $(p<0.05)$ of the packaging methods $\times$ storage time was observed for $L$ value, which is shown in Fig. 1. This figure illustrates

Table 1. Effect of packaging methods and storage time on the Hunter Lab attributes and TBA value of beef patties enhanced with flaxseed flour

\begin{tabular}{lcccc}
\hline \hline \multicolumn{1}{c}{ Factors } & $L^{\mathrm{l}}$ & $A^{2)}$ & $B^{3)}$ & TBA $^{4)}$ \\
\hline Packaging methods $(A)$ & $p<0.01$ & $p<0.01$ & $\mathrm{NS}$ & $p<0.01$ \\
AP $^{5)}$ & $35.28 \pm 1.07^{\mathrm{B}}$ & $7.77 \pm 0.63^{\mathrm{B}}$ & $10.35 \pm 0.52$ & $0.85 \pm 0.19^{\mathrm{A}}$ \\
$\mathrm{VP}^{6}$ & $36.05 \pm 0.67^{\mathrm{A}}$ & $9.54 \pm 0.95^{\mathrm{A}}$ & $10.01 \pm 0.51$ & $0.65 \pm 0.10^{\mathrm{B}}$ \\
MAP $^{7)}$ & $36.61 \pm 0.94^{\mathrm{A}}$ & $9.80 \pm 1.12^{\mathrm{A}}$ & $10.30 \pm 0.34$ & $0.66 \pm 0.11^{\mathrm{B}}$ \\
Storage time $(d)(B)$ & $\mathrm{NS}^{8)}$ & $p<0.01$ & $p<0.05$ & $p<0.01$ \\
1 & $36.32 \pm 1.10$ & $8.30 \pm 038^{\mathrm{B}}$ & $10.37 \pm 0.40^{\mathrm{A}}$ & $0.56 \pm 0.11^{\mathrm{D}}$ \\
4 & $36.15 \pm 0.75$ & $9.28 \pm 1.06^{\mathrm{A}}$ & $10.37 \pm 0.46^{\mathrm{A}}$ & $0.70 \pm 0.07^{\mathrm{C}}$ \\
7 & $35.79 \pm 1.30$ & $9.38 \pm 1.23^{\mathrm{A}}$ & $10.32 \pm 0.54^{\mathrm{A}}$ & $0.78 \pm 0.12^{\mathrm{B}}$ \\
10 & $35.66 \pm 0.96$ & $9.18 \pm 1.88^{\mathrm{A}}$ & $9.82 \pm 0.29^{\mathrm{B}}$ & $0.84 \pm 0.17^{\mathrm{A}}$ \\
A $\times$ B interaction & $p<0.05$ & $p<0.01$ & $\mathrm{NS}$ & $\mathrm{NS}$ \\
\hline
\end{tabular}

Values are means \pm standard deviation of three replicates.

A-D Means within the same factor and the same column with different superscript letters are different $(p<0.05)$.

${ }^{1)} L$, lightness $(100=$ white, $0=$ black $)$

${ }^{2)} a$, redness (+, red; -, green)

${ }^{3)} b$, yellowness (+, yellow; -, blue)

${ }^{4)} \mathrm{TBA}$, Thiobarbituric acid (mg MDA/kg sample)

${ }^{5)} \mathrm{AP}$, Aerobic packaging

${ }^{6}$ VP, Vacuum packaging

${ }^{7)}$ MAP, Modified atmosphere packaging $\left(75 \% \mathrm{~N}_{2}, 25 \% \mathrm{CO}_{2}\right)$

${ }^{8)} \mathrm{NS}$, Not significant $(p>0.05)$. 


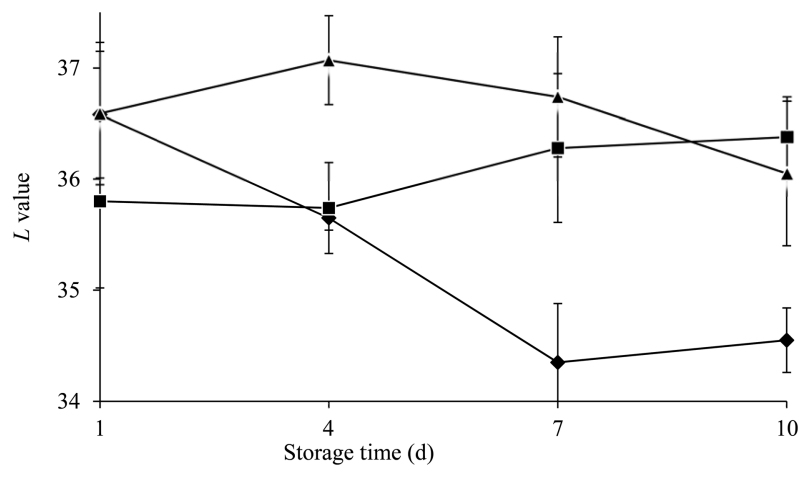

Fig. 1. Effect of packaging methods and storage time on $L$ value of beef patties treated with flaxseed flour. $(\diamond)$ aerobic packaging, ( $\boldsymbol{\square})$ vacuum packaging, ( $\boldsymbol{\Delta}$ ) modified atmosphere packaging.

that $L$ value of beef patties packaged in AP decreased until the $7 \mathrm{~d}$ of storage $(p<0.05)$ and then, remained constant $(p>0.05)$. However, $L$ value of beef patties packaged in MAP and VP did not show a significant change during storage $(p>0.05)$ and at the end of storage time, $L$ values of beef patties packaged in MAP and VP were 36.05 and 36.38 , respectively. These findings are similar to those of Morales-delaNuez et al. (2009) who reported that goat meat packaged in MAP and VP had higher L values than the samples packaged in AP. Also, $L$ values of dry fermented sausage packaged in MAP $\left(20 \% \mathrm{CO}_{2}+\right.$ $80 \% \mathrm{~N}_{2}$ ) and VP were similar have been reported by Rubio et al. (2008).

Redness ( $a$ value) is used as an indicator of colour stability in meat and meat products. As shown in Table 1, packaging treatment, storage time and interaction of packaging methods $\times$ storage time had very significant effects $(p<0.01)$ on $a$ value. Redness of beef patties packaged in MAP and VP were higher $(p<0.05)$ than that of the samples packaged in AP, and this could be attributable to oxidative reaction caused by oxygen. MoralesdelaNuez et al. (2009) reported that redness of goat meat packaged in AP was less than that of packaging in MAP and VP at $7 \mathrm{~d}$ of storage. Redness of beef patties packaged in MAP increased generally during storage time, while that of the samples packaged in VP increased until the $4 \mathrm{~d}$ of storage $(p<0.05)$ and then, remained constant $(p>0.05)$ (Fig. 2). Various researchers observed increases in the redness of meat and meat products packaged in MAP and VP during storage time (Morales-delaNuez et al., 2009; Rubio et al., 2008).

Packaging methods had no significant effect $(p>0.05)$, while storage time had a significant effect $(p<0.05)$ on $b$ value of beef patties enhanced with flaxseed flour (Table

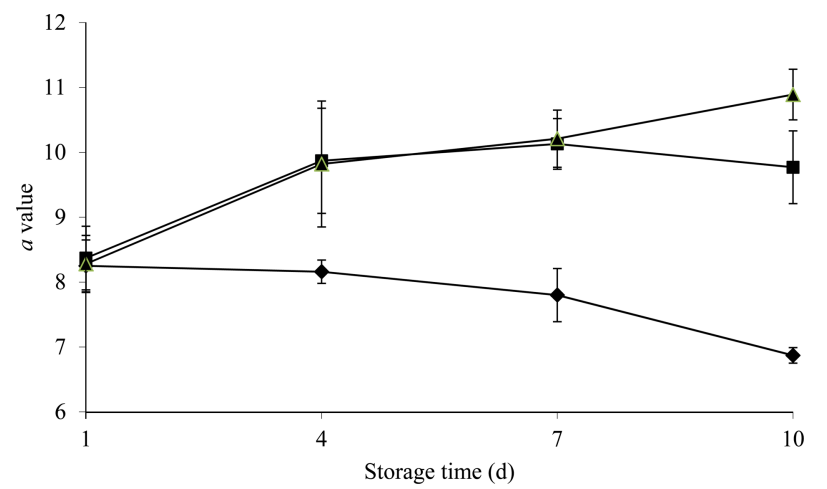

Fig. 2. Effect of packaging methods and storage time on $a$ value of beef patties treated with flaxseed flour. $(\diamond)$ aerobic packaging, ( $\boldsymbol{\square})$ vacuum packaging, ( $(\boldsymbol{\Delta})$ modified atmosphere packaging.

1). $b$ value at $10 \mathrm{~d}$ of storage was lower than other $\mathrm{d}$, but there were no differences in $b$ value among 1,4 and $7 \mathrm{~d}$ of storage. According to this, storage time did not determine clear changes in $b$ value.

Lipid oxidation promotes rancidity problems which are considered unpleasant for consumers and is related to the discolouration of meat (Parra et al., 2010). TBA test is one of the most widely used tests for evaluating the extent of lipid oxidation (Nawar, 1996). As shown in Table 1, packaging treatment and storage time had a significant $(p<0.01)$ effect on TBA values of beef patties. The lowest TBA value ( $0.65 \mathrm{mg} \mathrm{MDA} / \mathrm{kg}$ sample) occurred in the beef patties packaged in VP, but no significant difference with packaged in MAP was observed ( $p>0.05)$. The highest TBA value ( $0.85 \mathrm{mg} \mathrm{MDA} / \mathrm{kg}$ sample) occurred in beef patties packaged in AP $(p<0.05)$. According to these results, packaging with VP and MAP achieved $22-24 \%$ decrease in TBA value with respect to packaging in AP. Presence of oxygen in the package atmosphere is the determining factor for the rate of lipid oxidation (Fernandez-Lopez et al., 2008; Ordonez and Ledward, 1977; Seydim et al., 2006). Excluding or limiting the oxygen content in the VP and MAP atmospheres limited oxidation and thus resulted in lower TBA values for these beef patties. Decrease in TBA value of meat and meat products packaged in low oxygen concentration was also determined by various authors (Esmer et al., 2011; Fernandez-Lopez et al., 2008; Gok et al., 2008; Seydim et al., 2006).

Lipid oxidation (TBA values) for beef patties increased steadily from $0.56 \mathrm{mg} \mathrm{MDA} / \mathrm{kg}$ on the 1 st day to $0.84 \mathrm{mg}$ MDA $/ \mathrm{kg}$ on the 10th day of storage $(p<0.05)$ (Table 1). During the $10 \mathrm{~d}$ storage, TBA values of beef patties were increased approximately $33 \%$. High percentage of PUFA, 
mainly C18:2n-6 and C18:3n-3, probably made beef patties enhanced with flaxseed more susceptible to oxidation. Also, heme iron is one of the main catalysts for oxidative rancidity in meats (Seydim et al., 2006). According to Ockerman (1976) meat products with MDA concentration higher than $1 \mathrm{mg} / \mathrm{kg}$ are considered rancid. MDA contents of beef patties enhanced with flaxseed flour did not reach this value until the end of the storage time.

On the other hand, Pearson's correlation test indicated that TBA values were correlated with $a$ values $(\mathrm{r}=-0.340$; $p<0.05)$. These results indicated that TBA value may be used as indicator of discolouration in beef patties. Similarly, Parra et al. (2010) reported that a significant correlation was found between $a$ and TBARs values ( $p<0.001$; $\mathrm{r}=-0.197)$.

\section{Fatty acid composition}

The effect of packaging methods and storage time on the saturated fatty acid (SFA), MUFA and PUFA composition of beef patties enhanced with flaxseed flour are shown in Tables 2, 3 and 4, respectively. The fatty acid compositions were similar among the treatment groups $(p>0.05)$. These results agree with those pointed out by Rubio et al. (2008), who did not find differences among packaging systems (vacuum and $20 \% \mathrm{CO}_{2} / 80 \% \mathrm{~N}_{2}$ ) for C14:0, C16:0, C16:1, C17:0, C18:0, C18:1, C18:2, C18:3 and $\mathrm{C} 20: 1$ in dry fermented sausages manufactured with a high level of mono and polyunsaturated fatty acids. In all beef patties enhanced with flaxseed flour the predominant SFA were palmitic (16:0) and stearic acid (18:0), the most abundant MUFA was oleic acid (18:1n-9) and the predominant PUFA were linoleic (18:2n-6c) and lino-

Table 2. Effect of packaging methods and storage time on saturated fatty acid composition of beef patties enhanced with flaxseed flour ( $\mathrm{g} / \mathbf{1 0 0} \mathrm{g}$ fatty acids)

\begin{tabular}{lccccccccc}
\hline \hline \multicolumn{1}{c}{ Factors } & C10:0 & C12:0 & C14:0 & C15:0 & C16:0 & C17:0 & C18:0 & C20:0 $^{\text {SFA }}{ }^{1)}$ \\
\hline Packaging methods $(A)$ & $\mathrm{NS}^{5)}$ & NS & NS & NS & NS & NS & NS & NS & NS \\
AP $^{2}$ & $0.04 \pm 0.01$ & $0.05 \pm 0.01$ & $2.39 \pm 0.25$ & $0.36 \pm 0.03$ & $22.90 \pm 1.65$ & $1.03 \pm 0.06$ & $20.14 \pm 0.60$ & $0.21 \pm 0.02$ & $47.10 \pm 1.34$ \\
VP $^{3)}$ & $0.04 \pm 0.01$ & $0.05 \pm 0.02$ & $2.37 \pm 0.25$ & $0.36 \pm 0.04$ & $22.75 \pm 1.66$ & $1.05 \pm 0.07$ & $20.37 \pm 1.06$ & $0.21 \pm 0.02$ & $47.21 \pm 0.90$ \\
MAP $^{4)}$ & $0.04 \pm 0.01$ & $0.05 \pm 0.01$ & $2.35 \pm 0.22$ & $0.36 \pm 0.03$ & $22.67 \pm 1.66$ & $1.07 \pm 0.08$ & $20.67 \pm 0.25$ & $0.22 \pm 0.02$ & $47.42 \pm 2.00$ \\
Storage time $(d)(B)$ & NS & NS & NS & NS & NS & NS & NS & NS & NS \\
1 & $0.04 \pm 0.01$ & $0.05 \pm 0.01$ & $2.48 \pm 0.25$ & $0.38 \pm 0.04$ & $23.56 \pm 1.80$ & $1.07 \pm 0.08$ & $20.13 \pm 0.88$ & $0.20 \pm 0.02$ & $47.90 \pm 1.68$ \\
10 & $0.04 \pm 0.01$ & $0.05 \pm 0.01$ & $2.26 \pm 0.15$ & $0.34 \pm 0.02$ & $21.99 \pm 0.73$ & $1.03 \pm 0.05$ & $20.66 \pm 0.39$ & $0.22 \pm 0.01$ & $46.58 \pm 0.62$ \\
A $\times$ B interaction & $N S$ & NS & NS & NS & NS & NS & NS & NS & NS \\
\hline
\end{tabular}

Values are means \pm SD of three replicates.

${ }^{1)}$ SFA, Saturated fatty acids $(\mathrm{C} 10: 0+\mathrm{C} 12: 0+\mathrm{C} 14: 0+\mathrm{C} 15: 0+\mathrm{C} 16: 0+\mathrm{C} 17: 0+\mathrm{C} 18: 0+\mathrm{C} 20: 0)$

${ }^{2)}$ AP, Aerobic packaging

${ }^{3)} \mathrm{VP}$, Vacuum packaging

${ }^{4)}$ MAP, Modified atmosphere packaging $\left(75 \% \mathrm{~N}_{2}, 25 \% \mathrm{CO}_{2}\right)$

${ }^{5)} \mathrm{NS}$, Not significant $(p>0.05)$.

Table 3. Effect of packaging methods and storage time on monounsaturated fatty acid composition of beef patties enhanced with flaxseed flour ( $\mathrm{g} / \mathbf{1 0 0} \mathrm{g}$ fatty acids)

\begin{tabular}{ccccccc}
\hline \hline \multicolumn{1}{c}{ Factors } & C14:1 & C15:1 & C16:1 & C18:1n-9 & C20:1n-9 & MUFA $^{1)}$ \\
\hline Packaging methods $(A)$ & $\mathrm{NS}^{5)}$ & $\mathrm{NS}$ & $\mathrm{NS}$ & $\mathrm{NS}$ & $\mathrm{NS}$ & NS \\
AP $^{2}$ & $0.23 \pm 0.02$ & $0.27 \pm 0.03$ & $2.95 \pm 0.15$ & $39.55 \pm 1.42$ & $0.31 \pm 0.05$ & $43.31 \pm 1.33$ \\
$\mathrm{VP}^{3)}$ & $0.24 \pm 0.03$ & $0.28 \pm 0.03$ & $2.95 \pm 0.21$ & $39.71 \pm 1.30$ & $0.31 \pm 0.05$ & $43.48 \pm 1.11$ \\
MAP $^{4)}$ & $0.24 \pm 0.03$ & $0.28 \pm 0.03$ & $2.88 \pm 0.12$ & $39.38 \pm 1.68$ & $0.30 \pm 0.06$ & $43.08 \pm 1.62$ \\
Storage time $(d)(B)$ & $\mathrm{NS}$ & $\mathrm{NS}$ & $\mathrm{NS}$ & $p<0.01$ & $p<0.05$ & $p<0.01$ \\
1 & $0.24 \pm 0.03$ & $0.29 \pm 0.03$ & $3.00 \pm 0.20$ & $38.65 \pm 1.47^{\mathrm{B}}$ & $0.28 \pm 0.06^{\mathrm{B}}$ & $42.46 \pm 1.34^{\mathrm{B}}$ \\
10 & $0.23 \pm 0.02$ & $0.27 \pm 0.02$ & $2.85 \pm 0.05$ & $40.44 \pm 0.48^{\mathrm{A}}$ & $0.33 \pm 0.01^{\mathrm{A}}$ & $44.12 \pm 0.50^{\mathrm{A}}$ \\
A $\times$ B interaction & $\mathrm{NS}$ & $\mathrm{NS}$ & $\mathrm{NS}$ & $\mathrm{NS}$ & $\mathrm{NS}$ & NS \\
\hline
\end{tabular}

Values are means \pm standard deviation of three replicates.

${ }^{A-B}$ Means within the same factor and the same column with different superscript letters are different $(p<0.05)$.

${ }^{1)}$ MUFA, Monounsaturated fatty acids $(\mathrm{C} 14: 1+\mathrm{C} 15: 1+\mathrm{C} 16: 1+\mathrm{C} 18: 1 \mathrm{n}-9+\mathrm{C} 20: 1 \mathrm{n}-9)$

${ }^{2)} \mathrm{AP}$, Aerobic packaging

${ }^{3)} \mathrm{VP}$, Vacuum packaging

${ }^{4)}$ MAP, Modified atmosphere packaging $\left(75 \% \mathrm{~N}_{2}, 25 \% \mathrm{CO}_{2}\right)$

${ }^{5)} \mathrm{NS}$, Not significant $(p>0.05)$. 
Table 4. Effect of packaging methods and storage time on polyunsaturated fatty acid composition of beef patties treated with flaxseed flour ( $\mathrm{g} / 100 \mathrm{~g}$ fatty acids)

\begin{tabular}{lcccccc}
\hline \hline \multicolumn{1}{c}{ Factors } & C18:2n-6t & C18:2n-6c & C18:3n-6 & C18:3n-3 & C20:3n-3 & PUFA ${ }^{1)}$ \\
\hline Packaging methods $(A)$ & $\mathrm{NS}^{5}$ & $\mathrm{NS}$ & $\mathrm{NS}$ & $\mathrm{NS}$ & $\mathrm{NS}$ & $\mathrm{NS}$ \\
$\mathrm{AP}^{2)}$ & $0.27 \pm 0.03$ & $2.60 \pm 0.14$ & $0.13 \pm 0.01$ & $3.87 \pm 0.25$ & $0.27 \pm 0.03$ & $7.14 \pm 0.40$ \\
$\mathrm{VP}^{3)}$ & $0.28 \pm 0.03$ & $2.52 \pm 0.13$ & $0.14 \pm 0.01$ & $3.56 \pm 0.25$ & $0.27 \pm 0.02$ & $6.76 \pm 0.33$ \\
MAP $^{4)}$ & $0.28 \pm 0.03$ & $2.57 \pm 0.20$ & $0.14 \pm 0.01$ & $3.80 \pm 0.30$ & $0.27 \pm 0.03$ & $7.05 \pm 0.55$ \\
Storage time $(d)(B)$ & $\mathrm{NS}$ & $\mathrm{NS}$ & $\mathrm{NS}$ & $\mathrm{NS}$ & $\mathrm{NS}$ & $\mathrm{NS}$ \\
1 & $0.26 \pm 0.04$ & $2.53 \pm 0.20$ & $0.13 \pm 0.01$ & $3.78 \pm 0.25$ & $0.26 \pm 0.03$ & $6.97 \pm 0.49$ \\
10 & $0.29 \pm 0.05$ & $2.59 \pm 0.09$ & $0.14 \pm 0.01$ & $3.70 \pm 0.33$ & $0.28 \pm 0.01$ & $6.99 \pm 0.42$ \\
A $\times$ B interaction & $\mathrm{NS}$ & $\mathrm{NS}$ & $\mathrm{NS}$ & $\mathrm{NS}$ & $\mathrm{NS}$ & $\mathrm{NS}$ \\
\hline
\end{tabular}

Values are means \pm standard deviation of three replicates.

${ }^{1)}$ PUFA, Polyunsaturated fatty acids (C18:2n-6t+C18:2n-6c+C18:3n-6+C18:3n-3+C20:3n-3)

${ }^{2)} \mathrm{AP}$, Aerobic packaging

${ }^{3)} \mathrm{VP}$, Vacuum packaging

${ }^{4)}$ MAP, Modified atmosphere packaging $\left(75 \% \mathrm{~N}_{2}, 25 \% \mathrm{CO}_{2}\right)$

${ }^{5)} \mathrm{NS}$, Not significant $(p>0.05)$.

lenic acid (18:3n-3). Similar results were obtained by various researchers in beef patties formulated with different levels of flaxseed flour (Bilek and Turhan, 2009), in Dutch style fermented sausages with added flaxseed oil (Pelser et al., 2007) and in cooked pork sausages containing linseed oil (Valencia et al., 2008).

Storage time had no significant $(p>0.05)$ effect on SFA and PUFA amount, while 18:1n-9 ( $p<0.01), 20: 1 \mathrm{n}-9$ ( $p<$ $0.05)$ and MUFA amounts changed significantly $(p<0.01)$ during storage time. Similar to our results, changes in 18:1 and 20:1 during storage time of dry fermented sausages manufactured with a high level of mono and polyunsaturated fatty acids were reported by Rubio et al. (2008).

\section{Microbiological analysis}

Very significant effect $(p<0.01)$ of packaging methods on total aerobic mesophilic bacteria (TAMB) counts can be seen in Table 5. The lowest TAMB count was observed in the beef patties packaged in MAP, while the highest TAMB count was observed in the beef patties packaged in AP $(p<0.05)$. The TAMB count of beef patties packaged in VP was lower than that of the beef patties packaged in $\mathrm{AP}(p<0.05)$. Storage time had a very significant $(p<0.01)$ effect of TAMB counts. Also, an interaction $(p<0.05)$ between packaging methods and storage time noted for TAMB counts is shown in Fig. 3. According to this figure, the initial TAMB counts in the beef patties were quite high possible because of a high level of con-

Table 5. Effect of packaging methods and storage time on the microbiological counts of beef patties treated with flaxseed flour (Log CFU/g)

\begin{tabular}{lcccc}
\hline \hline \multicolumn{1}{c}{ Factors } & TAMB $^{1)}$ & Psychrotrophic bacteria & Coliform bacteria & S. aureus \\
\hline Packaging methods $(A)$ & $p<0.01$ & $p<0.01$ & $p<0.01$ & $p<0.01$ \\
AP $^{5)}$ & $8.01 \pm 0.85^{\mathrm{A}}$ & $8.03 \pm 0.80^{\mathrm{A}}$ & $4.22 \pm 0.81^{\mathrm{A}}$ & $3.02 \pm 0.22^{\mathrm{A}}$ \\
VP $^{6}$ & $7.81 \pm 0.90^{\mathrm{B}}$ & $7.70 \pm 0.77^{\mathrm{B}}$ & $3.75 \pm 0.33^{\mathrm{B}}$ & $2.69 \pm 0.13^{\mathrm{B}}$ \\
MAP $^{7)}$ & $7.39 \pm 0.62^{\mathrm{C}}$ & $7.40 \pm 0.62^{\mathrm{C}}$ & $3.51 \pm 0.29^{\mathrm{C}}$ & $2.71 \pm 0.20^{\mathrm{B}}$ \\
Storage time $(d)(B)$ & $p<0.01$ & $p<0.01$ & $p<0.05$ & $p<0.01$ \\
1 & $6.79 \pm 0.17^{\mathrm{D}}$ & $6.85 \pm 0.19^{\mathrm{D}}$ & $3.26 \pm 0.07^{\mathrm{D}}$ & $2.73 \pm 0.14^{\mathrm{C}}$ \\
4 & $7.37 \pm 0.39^{\mathrm{C}}$ & $7.40 \pm 0.40^{\mathrm{C}}$ & $3.65 \pm 0.26^{\mathrm{C}}$ & $2.86 \pm 0.20^{\mathrm{B}}$ \\
7 & $8.03 \pm 0.34^{\mathrm{B}}$ & $7.95 \pm 0.40^{\mathrm{B}}$ & $3.96 \pm 0.35^{\mathrm{B}}$ & $2.99 \pm 0.25^{\mathrm{A}}$ \\
10 & $8.75 \pm 0.48^{\mathrm{A}}$ & $8.63 \pm 0.43^{\mathrm{A}}$ & $4.44 \pm 0.73^{\mathrm{A}}$ & $2.64 \pm 0.22^{\mathrm{C}}$ \\
A $\times$ B interaction & $p<0.05$ & $\mathrm{NS}^{5}$ & $p<0.01$ & $\mathrm{NS}$ \\
\hline
\end{tabular}

Values are means \pm standard deviation of three replicates.

A-D Means within the same factor and the same column with different superscript letters are different $(p<0.05)$.

${ }^{1)}$ TAMB, Total aerobic mesophilic bacteria

${ }^{2)} \mathrm{AP}$, Aerobic packaging

${ }^{3)} \mathrm{VP}$, Vacuum packaging

${ }^{4)}$ MAP, Modified atmosphere packaging $\left(75 \% \mathrm{~N}_{2}, 25 \% \mathrm{CO}_{2}\right)$

${ }^{5)} \mathrm{NS}$, Not significant $(p>0.05)$. 


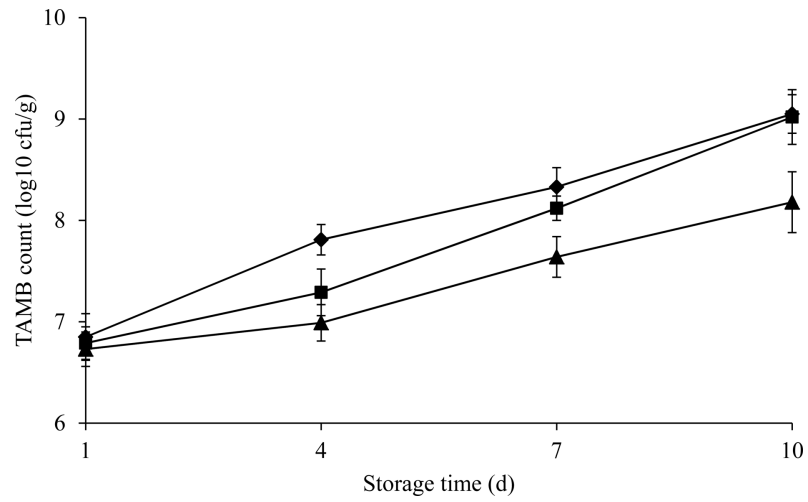

Fig. 3. Effect of packaging methods and storage time on total aerobic mesophilic bacteria (TAMB) counts of beef patties treated with flaxseed flour. $(\diamond)$ aerobic packaging, (ם) vacuum packaging, ( $\Delta$ ) modified atmosphere packaging.

tamination in the ground beef, beef fat, flaxseed flour and garlic powder. TAMB counts in all beef patties increased during storage time. However, the increase in beef patties packaged in MAP was lower than that of others during storage. TAMB counts of beef patties packaged in VP were lower than that of patties packages in AP until $7 \mathrm{~d}$ of storage $(p<0.05)$ and then, were similar $(p>0.05)$. It is assumed that vacuum reduces TAMB counts of beef patties until $7 \mathrm{~d}$ of storage due to the reduction of oxygen availability (Fernendez-Lopez et al., 2008; Mastromatteo et al., 2009). After $7 \mathrm{~d}$ of storage, TAMB counts of beef patties packaged in VP and AP were similar possible because of high oxygen permeability of polyamide bags. Final TAMB counts of the samples packaged in MAP, VP and AP reached 8.18, 9.02 and 9.05 Log CFU/g, respectively. According to these results, among the packaging methods studied, MAP had a significant effect on inhibiting of TAMB. Aerobic microorganisms are generally sensitive to $\mathrm{CO}_{2}$ (Ozogul et al., 2004); therefore, MAP delayed the bacterial growth. Delaying of bacterial growth in meat and meat products packaged in MAP including various $\mathrm{CO}_{2}$ contents was also previous reported in some studies i.e. in rabbit meat (Berruga et al., 2005), in Turkish pastirma (Gok et al., 2008) and in meatball (Ozturk et al., 2010). Microbial spoilage of meat usually occurs when TAMB reaches $10^{7}$ to $10^{8} \mathrm{CFU} / \mathrm{g}$ (Ozturk et al., 2010). TAMB counts of beef patties packaged in AP and VP exceeded $8 \mathrm{Log} \mathrm{CFU} / \mathrm{g}$ at the end of the $7 \mathrm{~d}$, while TAMB counts of beef patties packaged in MAP exceeded at the end of the $10 \mathrm{~d}$. Shelf-life extension of beef patties enhanced with flaxseed flour was best achieved at $75 \%$ $\mathrm{N}_{2}+25 \% \mathrm{CO}_{2}$ atmosphere.

Packaging methods had very significant $(p<0.01)$ effect on psychrotrophic bacterial counts (Table 5). Similar to TAMB counts, the lowest psychrotrophic bacterial count was in the beef patties packaged in MAP and the highest in the sample packaged in AP. The psychrotrophic bacterial count of beef patties packaged in VP was lower than that of the beef patties packaged in AP $(p<0.05)$. The initial psychrotrophic bacterial counts of the samples packaged in MAP, VP and AP was found to be average 6.85 Log CFU/g. Storage time had very significant $(p<0.01)$ effect of psychrotrophic bacterial counts (Table 5) and psychrotrophic bacterial counts in all beef patties increased during storage time. The increase of psychrotrophic bacteria counts was similar to TAMB counts.

Coliform bacteria are important microbiological sanitary indicators, which emphasizes hygiene in processing and handling of products (Filimon et al., 2010). As indicated in Table 5 , both packaging methods $(p<0.01)$ and storage time $(p<0.05)$ had a significant effect on coliform bacterial counts. The lowest coliform bacteria count observed the sample packaged in MAP was 3.51 Log CFU/ $\mathrm{g}$, while the highest coliform bacteria was observed in the beef patties packaged in AP $(p<0.05)$. Similar to TAMB and psychrotrophic bacteria counts, the coliform bacteria counts of beef patties packaged in VP was lower than that of the beef patties packaged in AP $(p<0.05)$. During storage time for $10 \mathrm{~d}$, coliform bacteria counts for beef patties increased steadily from 3.26 Log CFU/g to $4.44 \mathrm{Log}$ $\mathrm{CFU} / \mathrm{g}(p<0.05)$ (Table 5). Coliform counts were greater than the acceptable limit (3 Log CFU/g) (Irkin et al., 2011) in all storage times possible because of a high level of contamination in the ground beef, beef fat, flaxseed flour and garlic powder. Packaging methods $\times$ storage time interaction also had very significant effects $(p<0.01)$ on coliform bacteria counts. According to the Fig. 4,

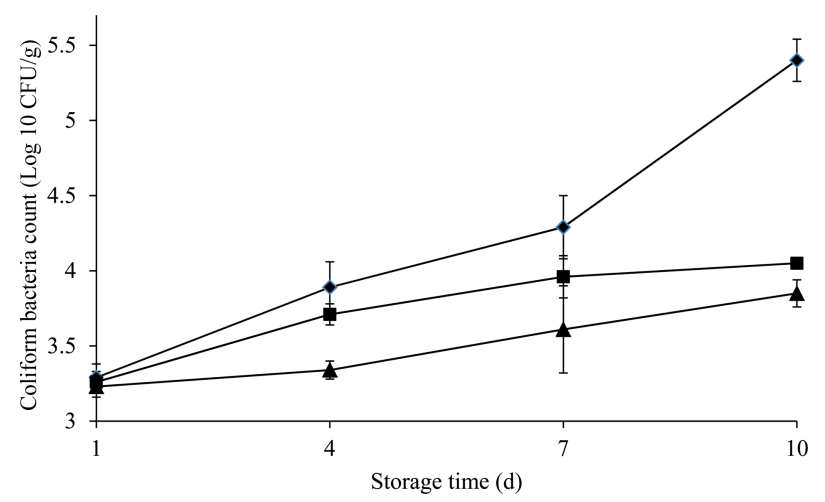

Fig. 4. Interaction effect of packaging methods and storage time on coliform bacteria counts of beef patties enhanced with flaxseed flour: $(\diamond)$ aerobic packaging, $(\square)$ vacuum packaging, ( $\Delta$ ) modified atmosphere packaging. 
there was an increase in coliform bacteria counts of all patty samples during storage time and the increase in beef patties packaged in MAP was lower than that of others. According to these results, among the packaging methods studied, packaging in MAP had a significant effect on inhibiting of coliform bacteria and it was followed by packaging in VP. Delaying of coliform bacteria growth in meat and fish packaged in MAP including various $\mathrm{CO}_{2}$ contents was also previous reported in some studies i.e. in red claw crayfish tails (Chen et al., 2007), in minced beef meat (Irkin et al., 2011) and in Baltic herring fillets (Randell et al., 1997).

Staphylococcus aureus is a common pathogen that causes foodborne illness. Very significant effects $(p<0.01)$ of packaging methods on $S$. aureus counts can be seen in Table 5. The highest count (3.02 Log CFU/g) was in samples packaging in AP and counts were greater than the maximum value (3 Log CFU/g) (Saucier et al., 2000). The lowest $S$. aureus count was observed in samples packaging in VP was 2.69 Log CFU/g, but no significant difference with packaging in MAP was observed $(p>0.05)$. Storage time had a very significant effect $(p<0.01)$ on $S$. aureus counts. $S$. aureus count increased steadily until the $7 \mathrm{~d}$ of storage $(p<0.05)$ and then, began to decrease. According to these results, among the packaging methods studied, packaging in VP and MAP had a significant effect on inhibiting of $S$. aureus.

The results of this study indicate that the shelf life of beef patties enhanced with flaxseed flour can be extended by packaging in MAP $\left(75 \% \mathrm{~N}_{2}, 25 \% \mathrm{CO}_{2}\right)$. This increase in shelf life is due to the reduction of not only microbial growth but also lipid oxidation. While, VP maintained the colour properties and lipid oxidation of beef patties, did not give good results in terms of the microbial growth. Furthermore, the samples packaged in VP lost their shape because of the compression by external atmosphere. Finally, the initial high microorganism counts of beef patties reduced the effectiveness of packaging methods.

\section{Acknowledgements}

The authors would like to thank Ondokuz Mayis University Research Foundation (PYO.MUH.1904.10.021) for financial support.

\section{References}

1. Arihara, K. (2006). Strategies for designing novel functional meat products. Meat Sci. 74, 219-229.
2. Berruga, M. I., Vergara, H., and Linares, M. B. (2005). Control of microbial growth and rancidity in rabbit carcasses by modified atmosphere packaging. J. Sci. Food Agr. 85, 19871991.

3. Bilek, A. E. and Turhan, S. (2009). Enhancement of the nutritional status of beef patties by adding flaxseed flour. Meat Sci. 82, 472-477.

4. Bligh, E. G. and Dyer, W. J. (1959). A rapid method of total lipid extraction and purification. Can. J. Biochem. Physiol. 37, 911-917.

5. Chen, G., Xiong, Y. L., Kong, B., Newman, M. C., Thompson, K. R., Metts, L. S., and Webster, C. D. (2007). Microbiological and physicochemical properties of red claw crayfish (Cherax quadricarinatus) stored in different package systems at $2^{\circ}$ C. J. Food Sci. 72, 442-449.

6. Esmer, O. K., Irkin, R., Degirmencioglu, N., and Degirmencioglu, A. (2011). The effects of modified atmosphere gas composition on microbiological criteria, color and oxidation values of minced beef meat. Meat Sci. 88, 221-226.

7. Fernandez-Gines, J. M., Fernandez-Lopez, J., Sayas-Barbera, E., and Perez-Alvarez, J. A. (2005). Meat products as functional foods: A review. J. Food Sci. 70, 37-43.

8. Fernandez-Lopez, J., Zhi, N., Aleson-Carbonell, L., PerezAlvarez, J. A., and Kuri, V. (2005). Antioxidant and antibacterial activities of natural extracts: Application in beef meatballs. Meat Sci. 69, 371-380.

9. Fernandez-Lopez, J., Sayas-Barbera, E., Munoz, T., Sendra, E., Navarro, C., and Perez-Alvarez, J. A. (2008). Effect of packaging conditions on shelf-life of ostrich steaks. Meat Sci. 78, 143-152.

10. Filimon, M. N., Borozan, A., Bordean, D., Radu, F., and Popescu, R. (2010). Microorganisms, qualitative, indicators for meat products. Anim. Sci. Biotechnol. 43, 346-349.

11. Gok, V., Obuz, E., and Akkaya, L. (2008). Effects of packaging method and storage time on the chemical, microbiological and sensory properties of Turkish pastirma- A dry cured beef product. Meat Sci. 80, 335-344.

12. Jimenez-Colmenero, F., Carballo, J., and Cofrades, S. (2001). Healthier meat and meat products: their role as functional foods. Meat Sci. 59, 5-13.

13. Irkin, R., Esmer, O.K., Degirmencioglu, N., and Degirmencioglu, A. (2011). Influence of packaging conditions on some microbial properties of minced beef meat at $4^{\circ} \mathrm{C}$ storage. Bulg. J. Agric. Sci. 17, 655-663.

14. International Organization for Standardization, ISO (1978). Animal and Vegetable Fats and Oils - Preparation of Methyl Esters of Fatty Acids. Method ISO 5509. Geneve, p. 6.

15. Mastromatteo, M., Lucera, A., Sinigaglia, M., and Corbo, M. R., (2009). Microbiological characteristics of poultry patties in relation to packaging atmospheres. Int. J. Food Sci. Technol. 44, 2620-2628.

16. Morales-delaNuez, A., Moreno-Indias, I., Falcon, A., Arguello, A., Sanchez-Macias, D., Capote, J., and Castro, N. (2009). Effects of various packaging systems on the quality characteristic of goat meat. Asian Austral J. Anim. Sci. 22, 428-432.

17. Nawar, W. W. (1996). Lipids. In Fennema, O. R. (ed) Food 
Chemistry. CRC Press, NY, USA, p. 1069.

18. Ockerman, H. W. (1976). Quality Control of Postmortem Muscle and Tissue. PhD thesis. The Ohio State University, Columbus.

19. Ordonez, J. A. and Ledward, D. A. (1977). Lipid and myoglobin oxidation in pork stored in oxygen- and carbon dioxide-enriched atmospheres. Meat Sci. 1, 41-48.

20. Ozogul, F., Polat, A., and Ozogul, Y. (2004). The effects of modified atmosphere packaging and vacuum packaging on chemical, sensory and microbiological changes of sardines (Sardina pilchardus). Food Chem. 85, 49-57.

21. Ozturk, A., Yilmaz, N., and Gunes, G. (2010). Effect of different modified atmosphere packaging on microbial quality, oxidation and colour of a seasoned ground beef product (Meatball). Packag. Technol. Sci. 23, 19-25.

22. Parra, V., Viguera, J., Sanchez, J., Peinado, J., Esparrago, F., Gutierrez, J. I., and Andres, A.I. (2010). Modified atmosphere packaging and vacuum packaging for long period chilled storage of dry-cured Iberian ham. Meat Sci. 84, 760-768.

23. Pelser, W. M., Linssen, J. P. H., Legger, A., and Houben, J. H. (2007). Lipid oxidation in n-3 fatty acid enriched Dutch style fermented sausages. Meat Sci. 75, 1-11.

24. Randell, K., Hattula, T., and Ahvenainen, R. (1997). Effectof packaging method on the quality of rainbow trout and Baltic herring fillets. LWT-Food Sci. Technol. 30, 56-61.

25. Rubio, B., Martinez, B., Garcia-Cachan, M. D., Rovira, J., and Jaime, I. (2008). Effect of the packaging method and the storage time on lipid oxidation and colour stability on dry fermented sausage salchichon manufacturated with raw material with a high level of mono and polyunsaturated fatty acids. Meat Sci. 80, 1182-1187.

26. Saucier, L., Gendron, C., and Gariepy, C. (2000). Shelf life of ground poultry meat stored under modified atmosphere. Poultry Sci. 79, 1851-1856.

27. Scollan, N., Hocquette, J. F., Nuernberg, K., Dannenberger, D., Richardson, I., and Moloney, A. (2006). Innovations in beef production systems that enhance the nutritional and health value of beef lipids and their relationship with meat quality. Meat $S c i$. 74, 17-33.

28. Seydim, A. C., Acton, J. C., Hall, M. A., and Dawson, P. L. (2006). Effects of packaging atmospheres on shelf-life quality of ground ostrich meat. Meat Sci. 73, 503-510.

29. Tang, S., Sheehan, D., Buckley, D. J., Morrissey, P. A., and Kerry, J. P. (2001). Anti-oxidant activity of added tea catechins on lipid oxidation of raw minced red meat, poultry and fish muscle. Int. J. Food Sci. Tech. 36, 685-692.

30. Tarladgis, B. G., Watts, B. M., and Younathan, M. T. (1960). A distillation method for the quantitative determination of malonaldehyde in rancid foods. J. Am. Oil Chem. Soc. 37, 44-48.

31. Valencia, I., O’Grady, M. N., Ansorena, D., Astiasaran, I., and Kerry, J. P. (2008). Enhancement of the nutritional status and quality of fresh pork sausages following the addition of linseed oil, fish oil and natural antioxidants. Meat Sci. 80, 1046-1054.

(Received 2012.11.30/Revised 2013.2.1/Accepted 2013.2.6) 